\title{
Factors which Affect the Size of the Organisms and the Optical Density of Suspensions of Pseudomonas aeruginosa and Escherichia coli
}

\author{
By F. BERNHEIM \\ The Department of Physiology and Pharmacology, Duke University Medical Center, \\ Durham, North Carolina, U.S.A.
}

(Received 24, April 1962)

\section{SUMMARY}

When water-washed organisms of a strain of Pseudomonas aeruginosa were exposed to solutions of $\mathrm{NaCl}$ or sucrose, they shrank in size and became more dense. The optical density of suspensions increased rapidly. Pre-treatment of the organisms with various cations, surface-active agents and heat and cold, affected the reaction, and the organisms then behaved differently toward $\mathrm{NaCl}$ and sucrose. Some but not all of the effects observed with $\boldsymbol{P}$. aeruginosa were also observed with a strain of Escherichia coli.

\section{INTRODUCTION}

Mager, Kuczinski, Schatzberg \& Avi-Dor (1956) observed that the turbidity of water suspensions of many Gram-negative bacteria increased when the osmotic pressure was increased by the addition of either electrolytes or non-electrolytes. The magnitude of the effect varied with the age, the degree of viability and the $\mathrm{pH}$. Gram-positive bacteria did not show the turbidity change. Avi-Dor, Kuczinski, Schatzberg \& Mager (1956) studied the kinetics of the turbidity changes in suspensions of Pasteurella tularensis. The initial increase was rapid, caused by the loss of water from the organisms, which decreased in size. This was followed by a decrease in turbidity and the rate of this decrease was affected by compounds which altered the metabolism of the organisms. In the present work, turbidity changes were studied in suspensions of a strain of Pseudomonas aeruginosa, an organism very sensitive to osmotic effects, and in a strain of Escherichia coli.

\section{METHODS}

A strain of Pseudomonas aeruginosa which has been maintained in this laboratory for 15 years, was grown at $34^{\circ}$ for $24 \mathrm{hr}$. in Difco nutrient broth. The organisms were centrifuged down and washed twice with distilled water. In this process they lost potassium, an average of $5 \cdot 7 \mu \mathrm{mole} / 40 \mathrm{ml}$. of wash water, but were subsequently able to take up potassium when incubated with potassium salts. The determinations of potassium were made with a flame photometer. One ml. of final suspension in water was placed in each of a series of test tubes. Various compounds were added dissolved in 0.1 or $0.2 \mathrm{ml}$. and allowed to react with the organisms for $15 \mathrm{~min}$. at $\mathbf{2 3}^{\circ}$. Water was then added to a final volume of $10 \mathrm{ml}$. and the initial optical density (o.D.) read at $490 \mathrm{~m} \mu$ in a photocolorimeter. Solid $\mathrm{NaCl}$, sucrose and other substances 
were then added so that their final concentrations were $0 \cdot 1-0 \cdot 2 \mathrm{M}$ and the o.D. read as soon as solution was complete, usually within 40 sec. During this time the maximal increase in o.D. had already occurred, and in fact the increase could be detected by the naked eye within a few seconds after addition was made. The o.D. was then measured at intervals. In other experiments various compounds were added after the o.D. had been increased by $\mathrm{NaCl}$, sucrose, etc., and the rate of change as compared with the control was determined. The values are expressed as follows: a standard curve was obtained with different volumes of a suspension of untreated organisms. When the initial o.D. of an experimental series gave a reading corresponding to $1.0 \mathrm{ml}$. organisms in the standard curve it was given the value of 1.0, when the o.D. corresponded to $2.0 \mathrm{ml}$. organisms in the standard curve it was given the value of $\mathbf{2 \cdot 0}$.

Avi-Dor et al. (1956) showed that the increase in optical density is the result of a decrease in organism size caused by water loss. Electron-microscope pictures taken of control organisms and others which had been exposed to $0 \cdot 15 \mathrm{M}-\mathrm{NaCl}$ confirmed the decrease in size and showed an increase in density consistent with water loss (Pl. 1).

The effect of pre-incubation of Pseudomonas aeruginosa with potassium salts on the change in 0.D. caused by the addition of $0.1 \mathrm{M}-\mathrm{NaCl}$ or $0.2 \mathrm{M}$-sucrose

Table 1 shows the effects of allowing the organisms to react with $0.05 \mathrm{M}-\mathrm{KCl}$ for 15 min. before dilution and addition of either $\mathrm{NaCl}$ or sucrose. Two effects can be seen. (1) The initial o.D., i.e., before addition of salt or sucrose, was decreased by

Table 1. The effect of pre-incubation of Pseudomonas aeruginosa suspensions with $0.05 \mathrm{M}-\mathrm{KCl}$ on the increase in optical density (o.D.) values produced by $0.1 \mathrm{M}-\mathrm{NaCl}$ or $0.2 \mathrm{M}$-sucrose

$\begin{array}{lcccccc}\begin{array}{c}\text { Pre- } \\ \text { treatment }\end{array} & \text { Agent } & \overbrace{\text { Initial }}^{\text {o.d. values }} & \text { Zero time } & \text { Agent } & \overbrace{\text { Initial }}^{\text {Zero time }} \\ \text { None } & \mathrm{NaCl} & \mathbf{0 . 9 9} & \mathbf{1 . 7 2} & \text { Sucrose } & \mathbf{0 . 9 9} & \mathbf{1 . 7 5} \\ \mathrm{KCl} & \mathrm{NaCl} & \mathbf{0 . 9 5} & \mathbf{1 . 3 2} & \text { Sucrose } & \mathbf{0 . 9 5} & \mathbf{1 . 3 4}\end{array}$

pre-incubation with $\mathrm{KCl}$. This decrease was small but consistent and indicates an increase in size of organism as the result of the uptake of $\mathrm{K}^{+}$accompanied by water. (2) The increase in o.D. following the addition of salt or sucrose (zero time o.D.) was diminished by the pre-incubation with $\mathrm{KCl}$. Apparently an increase in intracellular potassium partially protected the organisms against the subsequent osmotic effect. That the pre-incubation was necessary is shown by the fact that $\mathrm{KCl}$ added to the organisms immediately before dilution and addition of sucrose had little effect on the zero time o.D.

Since potassium was taken up by the organisms when they were suspended in water it was of interest to determine whether it would be taken up by organisms suspended in sucrose. Sucrose was added to the diluted suspension of organisms, the o.D. read, $0.2 \mathrm{ml}$. of $0.5 \mathrm{M}-\mathrm{KCl}$ added, and the o.D. read again after $2 \mathrm{~min}$. There was a marked decrease in the o.D. reading, indicating an increase in organism size. Direct measurement of potassium uptake was not possible because of the sucrose, but the only reasonable mechanism to explain the effect is that $\mathbf{K}^{+}$ions 
accompanied by water entered the cell. Table 2 compares the effect of potassium with other monovalent cations which also increased the organism size, though at a slower rate.

The entrance of cations into the organisms is probably the result of an active process. Table 3 shows the evidence for this in the case of potassium. Potassium phosphate solution ( $\mathrm{pH} 7 \cdot 4$ ), was pre-incubated with the organisms for $15 \mathrm{~min}$. in the presence and absence of $40 \mu \mathrm{g}$. $\mathrm{KCN}$; the suspensions were then diluted and $\mathrm{NaCl}$ added. Cyanide prevented the effect of the potassium phosphate, presumably by inhibiting some metabolic activity necessary for the transport.

Table 2. The change in optical density (o.D.) values 2 min. after the addition of $0.2 \mathrm{ml}$. of $0.5 \mathrm{M}$-solutions of various monovalent cations to Pseudomonas aeruginosa organisms suspended in $10 \mathrm{ml}$. of $0.2 \mathrm{M}$-sucrose

$\begin{array}{cc}\text { Salt added } & \begin{array}{c}\text { Change in } \\ \text { o.d. value }\end{array} \\ \text { None } & \mathbf{0} \\ \text { LiCl } & -\mathbf{0 . 2 6} \\ \mathrm{NaCl} & -\mathbf{0 . 3 0} \\ \mathrm{KCl} & -\mathbf{0 . 3 4} \\ \mathrm{RbCl} & -\mathbf{0 . 2 0} \\ \mathrm{CsCl} & -\mathbf{0 . 2 0}\end{array}$

Table 3. The effect of pre-incubation of Pseudomonas aeruginosa suspension with 0.05 м-potassium phosphate solution ( $p H \mathrm{H} \cdot 4$ ) with and without $40 \mu \mathrm{g} . \mathrm{KCN}$ on the increase in optical density (o.D.) value produced by $0.1 \mathrm{M}-\mathrm{NaCl}$

\begin{tabular}{lccc} 
& \multicolumn{3}{c}{ O.D. values } \\
\cline { 2 - 4 } Pre-treatment & Initial & Zero time & 60 min. \\
None & 1.00 & $1 \cdot 70$ & 1.49 \\
K phosphate & 0.81 & 1.09 & 0.86 \\
KCN & 0.87 & 1.49 & 1.33 \\
KCN + phosphate & $\mathbf{0 . 8 7}$ & 1.48 & 1.30
\end{tabular}

When the organisms were placed in boiling water for $5 \mathrm{~min}$. the initial o.D. value was increased (Table 4). Addition of $\mathrm{NaCl}$ caused an immediate decrease followed by a slower decrease to that of the control (unboiled) o.D. value. Despite the denaturation of the proteins, changes in organism size are possible when sodium ions and water enter it. Lysis appears to play little part in this effect. It could not explain the rapid and slow components of the curve nor the fact that the change stopped when the control o.D. value was reached. When sucrose was used instead of $\mathrm{NaCl}$, a smaller decrease in o.D. occurred, indicating that the damaged membrane still presented a partial barrier to sucrose. The effect of heating the organisms to $50^{\circ}$ for 15 min. shows the difference between the effects of $\mathrm{NaCl}$ and sucrose more clearly (Table 4). The initial o.D. value was again increased. The effect of $\mathrm{NaCl}$ was minimal, but that of sucrose was only slightly less than it was on normal organisms.

The effect of freezing and thawing was somewhat different from that of heat (Table 4). The initial o.D. was not affected, but $\mathrm{NaCl}$ was unable to increase the o.D., which decreased progressively with time to $60-70 \%$ of the initial value; 
i.e. the organism had become much larger or some had been lysed. Sucrose, however, was still able to increase the o.D. and this value did not decline below that of the initial.

Table 4. The effect of heat and of freezing and tharwing suspensions of Pseudomonas aeruginosa on the change in optical density (o.D.) value produced by $0 \cdot 1 \mathrm{M}-\mathrm{NaCl}$ or 0.2 s-sucrose

\begin{tabular}{|c|c|c|c|c|c|c|}
\hline & & & Time & of observ & tion & \\
\hline & & Initial & Zero time & $\begin{array}{l}60 \text { min. } \\
\text {.D. value }\end{array}$ & $120 \mathrm{~min}$. & $180 \mathrm{~min}$ \\
\hline $\begin{array}{l}\text { None } \\
\text { Boiled } 5 \text { min. } \\
\text { None } \\
\text { Boiled } 5 \text { min. }\end{array}$ & $\begin{array}{l}\mathrm{NaCl} \\
\mathrm{NaCl} \\
\text { Sucrose } \\
\text { Sucrose }\end{array}$ & $\begin{array}{l}1 \cdot 10 \\
1 \cdot 65 \\
1 \cdot 08 \\
1 \cdot 65\end{array}$ & $\begin{array}{l}1 \cdot 82 \\
1 \cdot 26 \\
1 \cdot 71 \\
1 \cdot 55\end{array}$ & $\begin{array}{l}1 \cdot 71 \\
1 \cdot 16 \\
1 \cdot 43 \\
1 \cdot 48\end{array}$ & $\begin{array}{l}1 \cdot 53 \\
1 \cdot 10 \\
1 \cdot 43 \\
1 \cdot 43\end{array}$ & $\begin{array}{l}1 \cdot 43 \\
1 \cdot 00 \\
1 \cdot 43 \\
1 \cdot 43\end{array}$ \\
\hline $\begin{array}{l}\text { None } \\
\text { At } 50^{\circ} \text { for } 15 \mathrm{~min} \text {. } \\
\text { None } \\
\text { At } 50^{\circ} \text { for } 15 \mathrm{~min} \text {. }\end{array}$ & $\begin{array}{l}\mathrm{NaCl} \\
\mathrm{NaCl} \\
\text { Sucrose } \\
\text { Sucrose }\end{array}$ & $\begin{array}{l}1 \cdot 18 \\
1 \cdot 44 \\
1 \cdot 18 \\
1 \cdot 44\end{array}$ & $\begin{array}{l}1 \cdot 96 \\
1 \cdot 60 \\
1 \cdot 98 \\
1 \cdot 82\end{array}$ & $\begin{array}{l}1.72 \\
0.90 \\
1 \cdot 55 \\
1 \cdot 60\end{array}$ & $\begin{array}{l}1 \cdot 55 \\
0 \cdot 83 \\
1 \cdot 43 \\
1 \cdot 55\end{array}$ & $\begin{array}{l}1 \cdot 43 \\
0 \cdot 82 \\
1 \cdot 40 \\
1 \cdot 43\end{array}$ \\
\hline Freezing and thawing & $\begin{array}{l}\text { NaCl } \\
\text { Sucrose }\end{array}$ & $\begin{array}{l}1.09 \\
1.09\end{array}$ & $\begin{array}{l}0.86 \\
1.45\end{array}$ & $\begin{array}{l}0 \cdot 63 \\
1.09\end{array}$ & $\begin{array}{l}0.58 \\
1.09\end{array}$ & - \\
\hline
\end{tabular}

\section{The effect of organic anions}

Sodium succinate was compared to sodium chloride as the osmotic agent. The increase of o.D. value with $\mathrm{NaCl}$ at zero time was 0.86 and at $60 \mathrm{~min}$. it was 0.73 units; with sodium succinate the respective figures were 0.73 and $\mathbf{0 . 2 7}$ units. Similar results were obtained with the sodium salts, sodium pyruvate, formate, acetate, benzoate and salicylate. The organic anions, whether possible sources of energy or not, caused a rapid decrease in o.D. to the initial value.

\section{The effect of EDTA, benzalkonium chloride and sodium alkylbenzene sulphonate}

These compounds were added to the organism suspension $15 \mathrm{~min}$. before dilution and addition of $\mathrm{NaCl}$ or sucrose. EDTA (ethylenediaminetetra-acetic acid) and benzalkonium chloride increased the initial O.D.; $\mathrm{Na}$ alkylbenzene sulphonate had no effect on it. EDTA partially inhibited the rise in o.D. with $\mathrm{NaCl}$, and the decrease in o.D. with time was more rapid. EDTA had no effect on the action of sucrose. After benzalkonium chloride, $\mathrm{NaCl}$ caused only a decrease in o.D. as if the barrier to its entry were eliminated, but the response to sucrose was little affected. After alkylbenzene sulphonate, $\mathrm{NaCl}$ produced a normal increase in O.D. but the subsequent decrease in o.D. was more rapid than usual. At the concentration used this anionic detergent did not prevent the initial effect of $\mathrm{NaCl}$ but did allow the subsequent more rapid entry of the salt into the organisms. Again the action of sucrose was not affected. These results are shown in Table 5.

All the effects of sucrose listed above were observed with glucose. The effects of $\mathrm{KCl}$ were the same as those of $\mathrm{NaCl}$ except that the decrease in o.D. with time was more rapid.

Experiments were done with a strain of Escherichia coli obtained from the clinical laboratory and the differences between it and the Pseudomonas aeruginosa can be 
summarized as follows. Sodium chloride increased the o.D. but the percentage increase was $15 \%$ smaller than that produced in $\boldsymbol{P}$. aeruginosa. Osmolar sucrose had only a slight transient effect. Apparently $\boldsymbol{E}$. coli is readily permeable to sucrose. Glucose increased the o.D. with $\boldsymbol{E}$. coli to the same extent as did $\mathrm{NaCl}$. Sodium succinate and pyruvate were as effective as $\mathrm{NaCl}$ but sodium formate, acetate and benzoate were inactive. Heating to $50^{\circ}$ and freezing and thawing were without effect, but after boiling, $E$. coli behaved like $P$. aeruginosa. EDTA and alkylbenzene sulphonate in the concentrations used, had no effect but benzalkonium chloride was active.

Table 5. The effect of pre-incubation of suspensions of Pseudomonas aeruginosa with EDT $A$, benzalkonium chloride $(B A)$ and sodium alkylbenzene sulphonate $(A S)$ on the change in optical density (o.D.) values produced by $0.1 \mathrm{M}-\mathrm{NaCl}$ or sucrose

In these experiments the osmolarity of sucrose was half that of $\mathrm{NaCl}$.

\begin{tabular}{|c|c|c|c|c|c|}
\hline \multirow{3}{*}{ Pre-treatment } & \multirow{3}{*}{ Agent } & \multicolumn{4}{|c|}{ Time of observation } \\
\hline & & \multirow[t]{2}{*}{ Initial } & \multicolumn{2}{|c|}{$\begin{array}{c}\text { Zero time } 60 \mathrm{~min} . \\
\text { o.D. value }\end{array}$} & \multirow[t]{2}{*}{$120 \mathrm{~min}}$. \\
\hline & & & & & \\
\hline None & $\mathrm{NaCl}$ & $1 \cdot 08$ & $2 \cdot 12$ & $2 \cdot 01$ & $1 \cdot 89$ \\
\hline EDTA $50 \mu \mathrm{g}$. & $\mathrm{NaCl}$ & $1 \cdot 26$ & $1 \cdot 72$ & $1 \cdot 36$ & $1 \cdot 26$ \\
\hline None & Sucrose & 1.08 & 1.87 & $1 \cdot 65$ & 1.54 \\
\hline EDTA $50 \mu \mathrm{g}$. & Sucrose & $1 \cdot 26$ & $1 \cdot 89$ & $1 \cdot 65$ & $1 \cdot 62$ \\
\hline None & $\mathrm{NaCl}$ & 0.73 & 1.35 & $1 \cdot 18$ & $1 \cdot 17$ \\
\hline BA $50 \mu \mathrm{g}$. & $\mathrm{NaCl}$ & 0.95 & 0.68 & 0.53 & 0.53 \\
\hline None & Sucrose & $0 \cdot 73$ & $1 \cdot 25$ & $1 \cdot 09$ & $1 \cdot 00$ \\
\hline BA $50 \mu \mathrm{g}$. & Sucrose & 0.99 & $1 \cdot 34$ & 0.95 & 0.93 \\
\hline None & $\mathbf{N a C l}$ & $\mathbf{1 \cdot 2 6}$ & 1.95 & $1 \cdot 72$ & $1 \cdot 64$ \\
\hline AS $120 \mu \mathrm{g}$. & $\mathbf{N a C l}$ & $1 \cdot 26$ & 1.95 & $\mathbf{1 . 3 5}$ & $1 \cdot 18$ \\
\hline None & Sucrose & 1.26 & $2 \cdot 01$ & $1 \cdot 82$ & 1.72 \\
\hline AS $120 \mu \mathrm{g}$. & Sucrose & $1 \cdot 26$ & $2 \cdot 01$ & 1.78 & 1.72 \\
\hline
\end{tabular}

\section{DISCUSSION}

The osmotic effect produced by the various compounds on these bacteria depends on the characteristics of the cell membrane, i.e. its ability to impose a barrier to free diffusion. Urea, for instance, diffuses through most membranes and causes no change in o.D. when added to suspensions of these organisms. The results with this simple method show some interesting differences in membrane characteristics. For instance, Pseudomonas aeruginosa has a barrier to sucrose, Escherichia coli has not. Heat, and freezing and thawing destroy the barrier to cations but not to sucrose in $\boldsymbol{P}$. aeruginosa. Similar treatment had no effect on the ion barrier in $E$. coli. $\boldsymbol{P}$. aeruginosa is more sensitive to the action of surface-active agents than $E$. coli, and in the former organism these agents affect the barrier to cations at concentrations which do not affect the barrier to sucrose. When the organisms $\boldsymbol{P}$. aeruginosa and $\boldsymbol{E}$. coli were allowed to take up cations before being subjected to the osmotic shock the change in O.D. was smaller. Another factor which would impose a limit to change in size of organism is the elasticity of the cell wall; this might explain why an increase in osmolarity above the equivalent of $0.1 \mathrm{M}-\mathrm{NaCl}$ had little or no effect. The rate of decrease in o.D. following the initial increase seems to depend on 
several factors. First, the rate of cation uptake. When $\mathrm{NaCl}$ was used as the osmotic agent, the mean decrease in 0.D. in $60 \mathrm{~min}$. was 0.20 ; when $\mathrm{KCl}$ was used it was 0.38 units. Secondly, the nature of the anion. The rates of decrease of o.D. with $\mathrm{NaCl}, \mathrm{NaBr}$ and $\mathrm{NaNO}_{3}$ were the same. But when the anion was organic the rate of decrease was consistently more rapid. There is no obvious explanation for this. Finally, pre-treatment of $\boldsymbol{P}$. aeruginosa with EDTA or benzalkonium chloride increased the initial o.D. This implies that these agents allowed an outward diffusion of ions accompanied by water, with the consequent shrinking of the organisms.

\section{REFERENCES}

Avi-Dor, Y., Kuczinski, M., Schatzberg, G. \& Mager, J. (1956). Turbidity changes in bacterial suspensions: kinetics and relation to metabolic state. J. gen. Microbiol. 14, 76.

Mager, J., Kuczinski, M., Schatzberg, G. \& Avi-Dor, Y. (1956). Turbidity changes in bacterial suspensions in relation to osmotic pressure. J. gen. Microbiol. 14, 69.

\section{EXPLANATION OF PLATE 1}

Fig. 1. Electron-microscope picture of washed Pseudomonas aeruginosa organisms after suspension in water $\times \mathbf{1 6 , 8 0 0}$.

Fig. 2. After suspension in $0.15 \mathrm{M}-\mathrm{NaCl} \times 16,800$.

The pictures were taken by Dr J. R. Overman of the Department of Microbiology on an RCAEML electron microscope. 


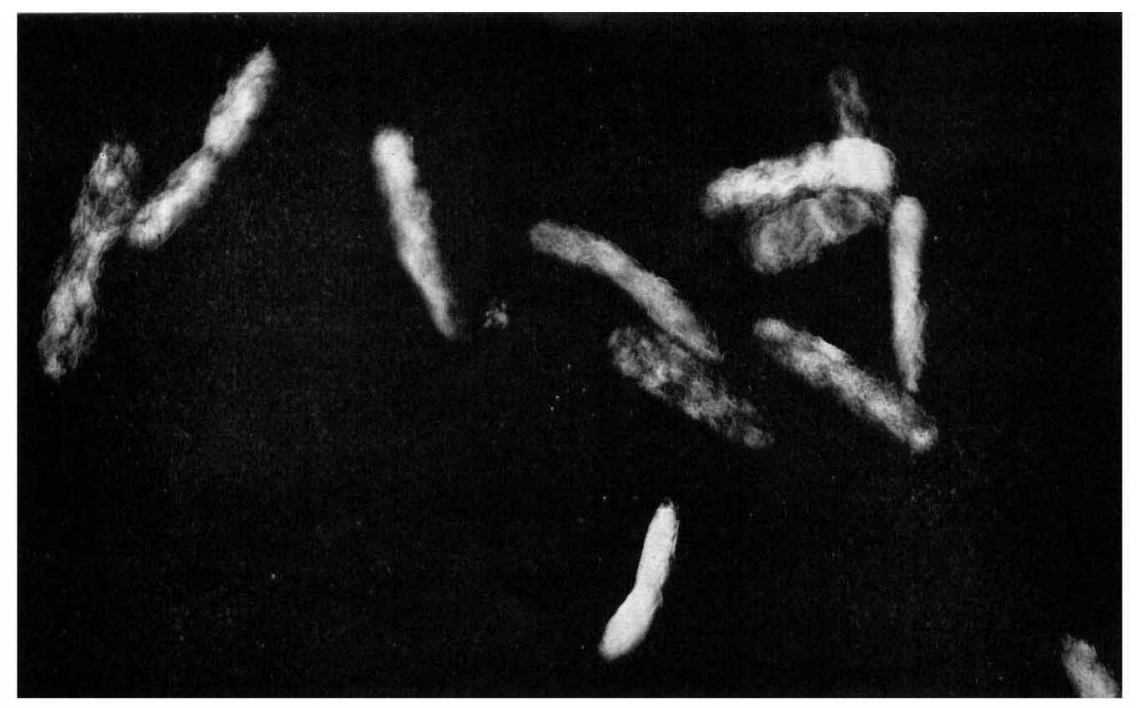

Fig. 1

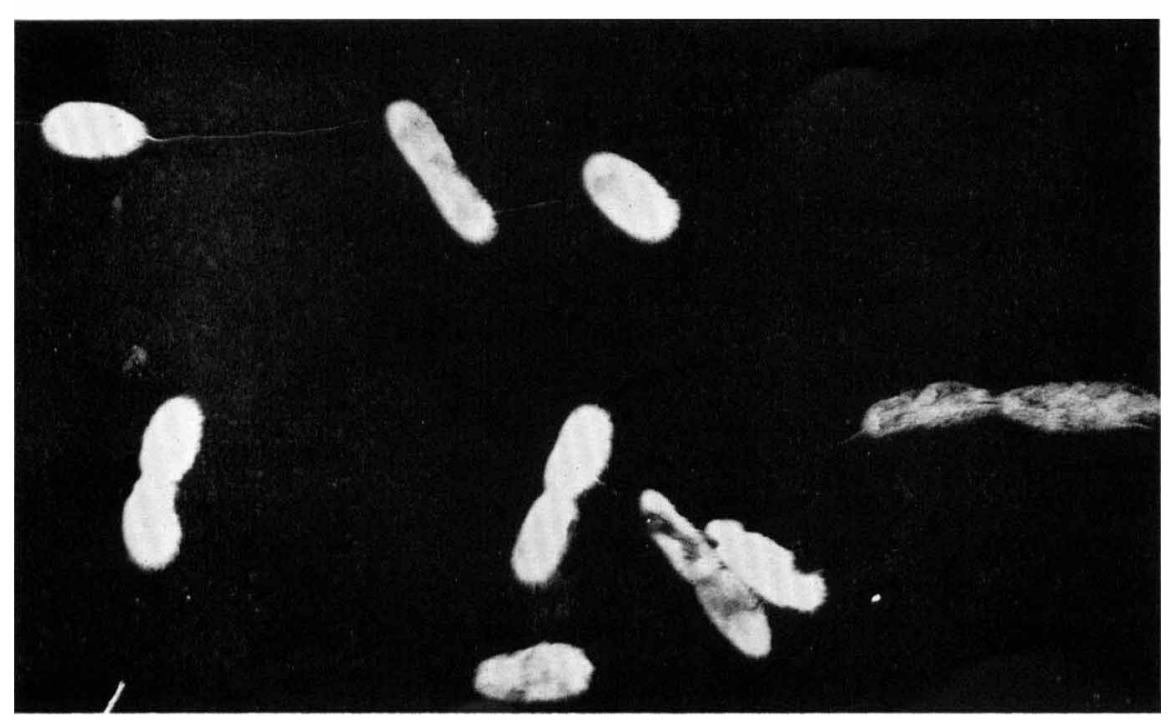

Fig. 2 